\title{
Atuação do enfermeiro na prevenção da lesão por pressão em pacientes acamados: revisão de literatura
}

The nurse's role in preventing pressure injuries in bedridden patients: literature review

El papel de la enfermera en la prevención de lesiones por presión en pacientes

encamados: revisión de la literatura

Eriolene de Jesus Pereira ${ }^{1 *}$, Marcia Silva Nogueira1.

\begin{abstract}
RESUMO
Objetivo: Descrever a atuação do enfermeiro na prevenção das lesões por pressão em pacientes acamados devido á incidência da mesma, por ser considerada um problema grave decorrente do âmbito hospitalar. Revisão bibliográfica: O presente estudo mostra que o papel do enfermeiro no controle da prevenção da lesão por pressão é primordial, identificando os fatores de risco que causam a lesão, conhecendo os graus da mesma, atuando com os cuidados de enfermagem e prevenindo o agravamento do caso. Pois o enfermeiro, juntamente com a equipe de saúde irão priorizar a prevenção de formação de lesões, agindo de maneira correta para que a pele do cliente acamado permaneça intacta, pois qualquer rompimento da integridade da pele. Considerações finais: Com a análise dos artigos, considerou-se que o enfermeiro com sua autonomia deve realizar abordagens de cuidado mais interativo e humanizados, direcionadas a prevenir e tratar de forma adequada o paciente portador de lesão por pressão.
\end{abstract}

Palavras-chave: Prevenção, Lesão por pressão, Papel do enfermeiro.

\begin{abstract}
Objective: Describe the role of nurses in the prevention of pressure injuries in bedridden patients due to its incidence, as it is considered a serious problem resulting from the hospital environment. Bibliographic review: The present study shows that the role of nurses in the control of pressure injury prevention is paramount, identifying the risk factors that cause the injury, knowing its degrees, working with nursing care and preventing the worsening of the injury. case. Because the nurse, together with the health team will prioritize the prevention of lesion formation, acting in a correct way so that the skin of the bedridden client remains intact, as any disruption of the skin's integrity. Final considerations: With the analysis of the articles, it was considered that nurses with their autonomy should perform more interactive and humanized care approaches, aimed at preventing and treating patients with pressure injuries adequately.
\end{abstract}

Key words: Prevention, Injuries of pressure, Role the nurse.

\section{RESUMEN}

Objetivo: Describa el papel de las enfermeras en la prevención de lesiones por presión en pacientes encamados debido a su incidencia, ya que se considera un problema grave como resultado del entorno hospitalario. Revisión bibliográfica: el presente estudio muestra que el papel de las enfermeras en el control de la prevención de lesiones por presión es primordial, identificando los factores de riesgo que causan la lesión, conociendo sus grados, trabajando con los cuidados de enfermería y evitando el empeoramiento de la lesión caso. Porque la enfermera, junto con el equipo de salud, priorizará la prevención de la formación de lesiones, actuando de manera correcta para que la piel del cliente postrado en cama permanezca intacta, como cualquier interrupción de la integridad de la piel. Consideraciones finales: con el análisis de los

${ }^{1}$ Centro Universitário ICESP, Brasília - DF. *E-mail: eriolenejesus@hotmail.com 
artículos, se consideró que las enfermeras con su autonomía deberían realizar enfoques de atención más interactivos y humanizados, destinados a prevenir y tratar a los pacientes con lesiones por presión de manera adecuada.

Palabras clave: Prevención, Lesiones por presión, Rol do enfermera.

\section{INTRODUÇÃO}

A pele é o maior órgão do corpo humano; anatomicamente, a epiderme é a camada externa e superficial da pele. Ela cobre a derme e hipoderme, tecidos mais profundos da pele (JUNQUEIRA LC e CARNEIRO J, 2013). A pele é uma defesa do corpo humano, pois protege as estruturas subjacentes contra a invasão de organismos. Partindo dessa premissa, as lesões por pressão significam um problema com potencial significante (POTTER PA e PERRY AG, 1999).

A lesão por pressão (LPP) é uma lesão localizada na pele ou tecidos subjacentes, normalmente sobre uma proeminência óssea, secundárias a um aumento de pressão externa, ou pressão em combinação com cisalhamento, que além de ocasionar dano tissular, pode provocar inúmeras complicações e agravar o estado clínico de pessoas com restrição na mobilização do corpo; segundo o American National Pressure Ulcer Panel (NPUAP) e European Pressure Ulcer Advisory Panel (IRION G, 2005).

Ela é considerada um problema grave, especialmente em pessoas idosas e pacientes portadores de doenças crônico degenerativas. Em muitos casos, são responsáveis pelas longas permanências hospitalares, em razão de uma recuperação lenta e sujeita a frequentes complicações, oriundas de quadros sépticos responsáveis pelas elevadas taxas de morbidade e mortalidade, ou de uma solução cirúrgica reparadora, conforme definição de Mélega JC (2002) é uma lesão que apresenta um período de desenvolvimento bastante rápido; após sua instalação, o paciente pode experimentar um período de hospitalização prolongado, causado pela própria lesão que, muitas vezes causa deformações e exposição a complicações mais sérias.

As lesões por pressão não ameaçam a vida num primeiro momento, mas é um problema que acarreta um desconforto ao paciente, dificultando o retorno ao convívio familiar e aumentando a probabilidade de infecção com agentes patogênicos podendo levar à morte. $O$ aparecimento de LPP se dá a partir de dois determinantes etiológicos críticos, a intensidade e a duração da pressão. Existem, ainda, os fatores extrínsecos e intrínsecos como: friç̧ão, cisalhamentos, umidade, redução ou perda da sensibilidade e força muscular e imobilidade (CREMASCO MF, et al., 2009).

O desenvolvimento da LPP é multifatorial, incluindo fatores internos e externos como: idade, morbidade, estado nutricional, hidratação, condições de mobilidade, nível de consciência, pressão, cisalhamento, fricção e umidade. Pacientes de Unidades de Terapia Intensiva (UTI) tem maior risco a desenvolver LPP pois a maioria, são pacientes hemodinamicamente instáveis, em uso de corticoides e drogas vasoconstrictoras, com a nutrição alterada, portadores de neoplasias e diabetes mellitus, idosos e restritos ao leito. A incidência de LPP em pacientes de UTI é mais elevada do que naqueles internados em outras unidades do hospital, devido aos vários fatores de risco a cima citados (FERNANDES NCS e TORRES GV, 2008).

Sabendo da magnitude do problema, que afeta diretamente o doente, seus familiares e a própria instituição, é necessário que o enfermeiro atue no intuito de prevenir a formação das lesões por pressão. Sendo assim o objetivo do presente trabalho é verificar através de revisão de literatura os principais métodos graus de lesão por pressão e a atuação do enfermeiro.

\section{REVISÃO BIBLIOGRÁFICA}

\section{A composição da pele}

A pele é o maior órgão do corpo humano e é essencial para a vida humana, pois atua formando um manto de revestimento do organismo e barreira entre os órgãos internos e o ambiente externo e participa em muitas funções orgânicas vitais, tem funções de proteção, termorregulação, percepção e secreção. A pele tem funções importantes no corpo uma vez que atua diretamente na proteção do organismo da invasão de 
microrganismos, permitem a sensação de temperatura, dor, toque suave e pressão, mantém o equilíbrio hídrico, regula a temperatura, converte substâncias que sintetizam a vitamina $D$ e, têm ainda, função de resposta imune (BRASIL, 2002; BRUNNER LS e SUDDARTH DS, 2011).

A pele é composta por três camadas, a saber: epiderme, derme e hipoderme ou tecido subcutâneo. A epiderme produz constantemente novas células as quais são impelidas à superfície. Contém filamentos de queratina que sustentam a pele, melanócitos produtores de melanina, bem como as células de Langerhns que exerce a função imunológica. A derme constitui-se de fibras colágenas e elásticas, ambas participam da fixação da epiderme a derme. Encontra-se ainda na derme vasos sanguíneos, linfáticos, terminações nervosas sensoriais, glândulas sebáceas e sudoríparas e pelos. A hipoderme ou tecido subcutâneo possui áreas secretoras das glândulas sudoríparas, vasos sanguíneos, pelos e terminações nervosas. Contribui para o isolamento térmico, proteção mecânica a pressão e traumas, depósito nutritivo de reserva, bem como, promove mobilidade da pele sobre estruturas subjacentes (SILVA RCL, et al., 2011).

O enfermeiro juntamente com a equipe de saúde tem como objetivo priorizar a prevenção de formação de ferida, agindo de maneira correta para que a pele do cliente acamado permaneça intacta, pois qualquer rompimento nessa integridade é potencialmente perigoso, causando uma série de implicações e gerando risco para o desenvolvimento de lesão por pressão.

\section{Lesão por Pressão}

A lesão por pressão é uma lesão localizada na pele, tecido, músculo e osso é entendida como uma lesão cutânea ocasionada por pressão intensa ou contínua, exercida em áreas de proeminência óssea, impedindo ou dificultando a perfusão tissular, levando à diminuição da circulação sanguínea e consequentemente a morte e necrose da pele (SCHWARTS AY, et al., 2007). Trata-se, então, de uma manifestação clínica da destruição tecidual localizada, decorrente da falta de fluxo sanguíneo em áreas sob pressão, podendo ocorrer em qualquer área do corpo tanto em adultos como em crianças, sendo mais frequente abaixo da linha da cintura e sobre proeminências ósseas, tais como a sacra, trocanteriana, tuberosidade isquiática, calcâneo, entre outras (MEDEIROS ABF e LOPES CHAF, 2009)

Segundo Costa FPP (2005), as lesões por pressão podem se desenvolver em 24 horas ou levar até 05 dias para sua manifestação e toda equipe de saúde é responsável pelo acompanhamento do paciente, devendo estar familiarizados com os principais fatores de risco. Nesse sentido, a observação das medidas profiláticas para eliminar forças de pressão contínua, cisalhamento ou fricção é de vital importância para evitar a formação de lesões.

Menegon DB (2007) relata que os enfermeiros são capacitados para avaliação de risco de lesão por pressão, além de possuir conhecimento técnico para a elaboração do diagnóstico de enfermagem de risco para prejuízo da integridade da pele. Louro M, et al. (2007) esclarecem que a Organização Mundial de Saúde (OMS) utiliza a incidência e a prevalência das lesões por pressão como um dos indicadores para determinar a qualidade dos cuidados prestados nas instituições hospitalares e que a maioria das lesões por pressão são evitáveis, tornando imprescindível utilizar todos os meios disponíveis para realizar uma eficaz prevenção e tratamento das lesões por pressão já estabelecidas.

\section{Fatores de Risco}

Em suas diretrizes internacionais de prevenção de lesão por pressão, a NPUAP e EPUAP recomendam o uso de uma abordagem estruturada para avaliação e identificação de indivíduos em risco de desenvolver lesão por pressão. São citados como maiores grupos de risco. Conforme os grupos relacionados, na tabela abaixo diz que os fatores de risco para lesões por pressão estão relacionados com: causas físicas de imobilidade como alterações no tônus muscular, sensibilidade reduzida, lesões traumáticas e outras doenças musculares; causas cognitivas de imobilidade que incluem nível de consciência alterado, coma, anestesia, dor; sensibilidade reduzida, ocasionada por lesões medulares e cerebrais, bem como neuropatias periféricas; umidade excessiva decorrente da incontinência urinária e fecal; edema; desnutrição; e problemas oriundos da assistência ao cliente, como falta de mudança de decúbito, superfícies de apoio inadequadas, higiene deficiente e déficits nos cuidados com a pele e lubrificação (IRION G, 2005). 
A avaliação diariamente da pele permite o enfermeiro identificar os fatores de risco para a realização de um diagnóstico correto gerando o tratamento eficaz e prevenção das lesões por pressão. A atuação sobre 0 controle desses fatores de risco determinará no sucesso do tratamento gerando melhora e cicatrização, ou agravamento das lesões por pressão. De acordo com a tabela a seguir observe as causas e motivos dos fatores de risco para lesões por pressão (Quadro 1).

Quadro 1 - Causas e motivos dos fatores de risco para lesões por pressão.

\begin{tabular}{|l|l|}
\hline Pessoas com lesão medular; & Perda da sensibilidade. \\
\hline Idoso incapacitado; & Causas físicas de imobilidade. \\
\hline Pessoa incapaz ou com dificuldade de mobilidade; & Alteração no tônus muscular. \\
\hline Incontinência urinária ou intestinal; & Decorrente de umidade excessiva. \\
\hline Tolerância tecidual reduzida; & Pele frágil. \\
\hline Desnutrição ou obesidade. & $\begin{array}{l}\text { Lubrificação das proeminências ósseas e falta } \\
\text { de mudança de decúbito. }\end{array}$ \\
\hline
\end{tabular}

Fonte: Pereira EJ e Nogueira MS, 2020; Baseado em Irion G, 2005.

\section{Prevenção de lesão por pressão}

A grande incidência e prevalência da lesão por pressão sugerem uma atuação insuficiente dos profissionais da saúde, junto aos pacientes hospitalizados e acamados por razões diversas. A equipe multidisciplinar deve estar integrada para prestar os cuidados aos pacientes acamados, que por ventura poderão apresentar riscos para integridade da pele e ainda ressalto a importância do enfermeiro como cuidador integral do paciente (MEDEIROS ABF, 2009). Observe a tabela a seguir sobre a prevenção das lesões por pressão (Quadro 2).

Quadro 2 - A prevenção das lesões por pressão pode ser feita de várias maneiras.

\begin{tabular}{|l|c|}
\hline \multicolumn{1}{|c|}{ Planejamento } & Intervenção \\
\hline $\begin{array}{l}\text { Realizar a avaliação do grau de risco com } \\
\text { individualização da assistência e a confecção de um } \\
\text { protocolo para prevenção de lesão por pressão; }\end{array}$ & Continuo. \\
\hline Utilizar escalas de avaliação do grau de risco; & Conforme POP. \\
\hline $\begin{array}{l}\text { Mapear individualmente as áreas suscetíveis à lesão } \\
\text { por pressão; }\end{array}$ & Continuo. \\
\hline Utilizar colchão piramidal (tipo colchão casca de ovo); & Sempre que necessário. \\
\hline $\begin{array}{l}\text { Mobilizar ou mudar o decúbito, realizando massagem } \\
\text { de conforto com emulsão; }\end{array}$ & De 2 em 2 hs. \\
\hline $\begin{array}{l}\text { Registrar as alterações da pele do paciente seguindo } \\
\text { os estágios de classificação das lesões; }\end{array}$ & $3 \mathrm{X}$ ao dia . \\
\hline
\end{tabular}

Fonte: Pereira EJ e Nogueira MS, 2020; Baseado em Medeiros ABF, 2009.

Considerando que a prevenção é o melhor passo a seguir, ressalto que os profissionais devem ser dotados de conhecimentos científicos e técnicos para que se obtenha um bom resultado e possa orientar a família de forma correta, impedindo que formem novas áreas de isquemia, mais lesões ou necrose no leito 2 da ferida que está sendo tratada, por isso, esse estudo é de suma importância para contribuir com a nossa área de atuação (IRION G, 2005).

\section{Escalas de risco para prevenção de lesão por pressão}

Muitos parâmetros são considerados durante a avaliação do cliente em risco de desenvolver lesões por pressão pelas escalas como imobilidade, incontinência, desnutrição e estado mental alterado, ocorrendo algumas diferenças entre uma escala e outra. Nesse estudo serão citados algumas escalas que são utilizadas pelo enfermeiro para avaliar o nível de risco de o cliente desenvolver uma lesão (MARCON SS, 2008). 
Escala de Braden foi criada por Braden e Bergstrom como iniciativa para reduzir a incidência e prevalência das lesões por pressão no serviço onde trabalhavam. Possui seis aspectos: percepção sensorial, umidade, atividade, nutrição, fricção e cisalhamento. Estes dois últimos pontos diferem das outras escalas, pois as outras não levam em conta a friç̧ão e o cisalhamento. As pontuações variam de 1 a 4 para cada item com exceção da fricção e cisalhamento, que vai de 1 a 3 . A escala mostra uma pontuação máxima de 23 e uma pontuação de 16 ou abaixo que geralmente é considerada uma condição de risco para o paciente,observe a seguir a tabela que descreve como analisar a escala de Braden (Quadro 3) (BERGSTROM N, 1987; BRADEN BJ, 1987).

Quadro 3 - Escala de Braden.

\begin{tabular}{|c|c|c|c|c|}
\hline & \multicolumn{4}{|c|}{ PONTUAÇÃO } \\
\hline & 1 & 2 & 3 & 4 \\
\hline $\begin{array}{l}\text { Percepção } \\
\text { sensorial }\end{array}$ & Totalmente limitado & Muito limitado & Levemente limitado & Nenhuma limitação \\
\hline Umidade & $\begin{array}{l}\text { Completamente } \\
\text { molhado }\end{array}$ & Muito molhado & $\begin{array}{l}\text { Ocasionalmente } \\
\text { molhado }\end{array}$ & $\begin{array}{l}\text { Raramente } \\
\text { molhado }\end{array}$ \\
\hline Atividade & Acamado & $\begin{array}{l}\text { Confinado á } \\
\text { cadeira }\end{array}$ & $\begin{array}{c}\text { Anda } \\
\text { ocasionalmente }\end{array}$ & $\begin{array}{c}\text { Anda } \\
\text { frequentemente }\end{array}$ \\
\hline Mobilidade & Totalmente & Bastante limitado & Levemente limitado & $\begin{array}{l}\text { Não apresenta } \\
\text { limitações }\end{array}$ \\
\hline Nutrição & Muito pobre & $\begin{array}{l}\text { Provavelmente } \\
\text { inadequada }\end{array}$ & Adequada & Excelente \\
\hline $\begin{array}{l}\text { Friccção e } \\
\text { cisalhamento }\end{array}$ & Problema & Problema potencial & Nenhum problema & --- \\
\hline TOTAL & $\begin{array}{l}\text { Risco brando } 15 \text { a } \\
16\end{array}$ & $\begin{array}{c}\text { Risco moderado } 12 \\
\text { a } 14\end{array}$ & $\begin{array}{l}\text { Risco severo } \\
\text { abaixo de } 11\end{array}$ & --- \\
\hline
\end{tabular}

Fonte: Pereira EJ e Nogueira MS, 2020; Adaptado de Hess Cathy T. Tratamento de feridas e úlceras, 1987.

Escala de Norton, o risco é determinado pela soma, ou seja, quanto menor a pontuação, maior o risco de aparecimento da lesão por pressão. Uma pontuação com total de 12 escores ou menos sinaliza um alto risco de formação da lesão por pressão. A seguir será descrita a escala de Norton (Quadro 4).

Quadro 4 - Escala de NORTON-Total de $-<12$ pontos= Correndo risco.

\begin{tabular}{|c|c|c|c|c|}
\hline Condições físicas & $\begin{array}{c}\text { Condições } \\
\text { mentais }\end{array}$ & Atividade & Mobilidade & Continência \\
\hline Boa 4 & Alerta 4 & Deambula 4 & Plena 4 & Boa 4 \\
\hline Razoável 3 & Apático 3 & $\begin{array}{c}\text { Deambula c/ ajuda } \\
3\end{array}$ & $\begin{array}{c}\text { Discretamente } \\
\text { limitada 3 }\end{array}$ & Ocasional 3 \\
\hline Ruim 2 & Confuso 2 & $\begin{array}{c}\text { Senta em uma } \\
\text { cadeira 2 }\end{array}$ & Muita limitada 2 & Frequente 2 \\
\hline Muito Ruim 1 & Torporoso 1 & $\begin{array}{c}\text { Permanece no leito } \\
1\end{array}$ & Imóvel 1 & Urinária e Fecal 1 \\
\hline Total & Total & Total & Total & Total \\
\hline
\end{tabular}

Fonte: Pereira EJ e Nogueira MS, 2020; Adaptado de Hess Cathy T. Tratamento de feridas e úlceras, 1987. 


\section{Estágios da lesão por pressão}

As lesões por pressão são as únicas feridas que são estagiadas. O estagiamento é realizado quando se examinam e registram as condições da ferida e são classificadas segundo critérios estabelecidos pela National Pressure Ulcer Advisory Panel em 1989, entidade norte americana, que discrimina quatro estágios observados visualmente na evolução de uma lesão por pressão.

Estágio I: a lesão envolve somente as camadas superficiais da pele, como a epiderme e a derme. Este estágio se caracteriza por temperatura cutânea elevada devido à vasodilatação aumentada, eritema que permanece por 15 minutos ou mais após o alívio da pressão no local, dor e discreto edema, posteriormente evolui para o aspecto mosqueado, cianótico, azul-acinzentado que é o resultado da oclusão dos capilares cutâneos e o enfraquecimento subcutâneo. Em geral, esses sinais de inflamação podem ser revertidos com a remoção da pressão no local (DYNAMED PLUS, 2017).

Estágio II: envolve o tecido subcutâneo exibindo uma ruptura na pele através da epiderme e derme. Caracteriza-se por abrasão, bolha ou cratera superficial, necrose juntamente com o represamento venoso e trombose, edema visível, dor, extravasamento de pouco exsudato e pele adjacente vermelha ou escurecida (CONCEIÇÃO GS, 2007).

Estágio III: derme e epiderme estão destruídas e a hipoderme é atingida, este estágio caracteriza-se por presença de drenagem de exsudato amarelado ou esverdeado com odor fétido, vesícula ou cratera não muito profunda, pontos de tecidos desvitalizados, ficando o paciente suscetível às infecções (LOURO M, 2007).

Estágio IV: representa destruição profunda dos tecidos, podendo atingir fáscia, envolver músculos, tendões e possivelmente osso e articulação. Caracteriza-se por tecido necrótico ou esfacelos, tunelização na ferida e drenagem de secreção com odor fétido (EBSERH, 2018).

\section{Tratamento e Coberturas}

Segundo Medeiros ABF (2009) um dos fatores que deve ser considerado no tratamento de lesões por pressão é a posição, graduação, aparência da lesão para que ocorra a seleção apropriada os produtos para tratamento das feridas. $O$ tratamento das lesões por pressão tem como objetivos proporcionar a cicatrização da lesão e impedir a gravidade e complicações decorrentes da ferida.

Tendo esse conhecimento em vista, o profissional avalia a ferida, procede ao estadiamento da lesão, mensuração e descrição do aspecto da mesma. Em seguida, inicia-se a fase de seleção do curativo que consiste no conhecimento das finalidades do curativo, propriedades e indicações dos mesmos. Vários são os produtos usados no tratamento e cuidado de uma lesão por pressão.

Cabe ao médico e ao enfermeiro especialista a escolha da cobertura que melhor atende a necessidade do cliente. É fundamental que o enfermeiro conheça cada cobertura e seu mecanismo de ação antes de utiliza-lo em uma lesão por pressão, por essa razão foi realizado um estudo sistêmico sobre as principais coberturas (DEALEY C , et al., 2005).

Carvão ativado com prata: tem a função de absorção de exsudato, quelagem do odor, bacteriostático e bactericida, é indicado em feridas infectadas, colonizadas, exsudativas e cavitárias, o carvão ativado age na captura as bactérias dentro da cobertura; a prata mata as bactérias; novamente o carvão age absorvendo partículas de odor e toxinas e pode permanecer por até 7 dias na ferida. Não é indicado em necrose, lesão isquêmica, os principais cuidados de enfermagem são uma cobertura primária e requer cobertura secundária, sendo usualmente gazes, que devem ser trocadas diariamente ou mais de uma vez ao dia, porém o carvão deverá ser trocado assim que atingir o ponto de saturação (BORGES E, 2008).

Ácidos Graxos Essenciais: tem a função de cicatrização, profilaxia de lesões por pressão é indicado na proteção, hidratação, restauração da pele e área receptora do enxerto. Prevenção e tratamento das LP de graus I, II, III. Tratamento de feridas crônicas ou agudas na ausência de processos infecciosos. Deve ser trocado a cada 24 horas, é contraindicado ao paciente com sensibilidade ao produto e os principais cuidados de enfermagem, cuidado para não promover trauma. Remover tecidos desvitalizados. Realizara limpeza com S.F. 0,9\% passar AGE sobre o tecido perilesional a lesão (BORGES E, 2008). 
Hidroalginato com Prata: a principal função é controlar eficazmente o exsudato em feridas infectadas ou fortemente colonizadas. É indicado no uso em lesões por pressão, lesões diabéticas, áreas doadoras, feridas traumática, feridas cirúrgicas, inicialmente o curativo deve ser trocado a cada 24 horas. É contraindicado em necrose, lesão isquêmica, hipersensibilidade a prata, gestantes e lactantes, queimaduras de $3^{\circ}$ grau. Os principais cuidados são o curativo deve ser removido antes de exames por ressonância magnética ou com eletrodos e gel condutor (CAMPEDELLI MC, 1987).

Alginato de Prata: é recomendado para o gerenciamento de feridas de espessura parcial a total, infectadas, não infectadas, tais como lesões por pressão de estágio I-IV, úlceras venosas, queimaduras de segundo grau e áreas doadoras de enxerto. A camada externa de espuma permite um excelente gerenciamento de exsudato, ajudando a reduzir o risco de maceração na área perilesiona. Aumento de absorção e do conforto, maior tempo de uso, menor número de trocas e, consequentemente, redução dos custos do tratamento.

A troca deve ser realizada a cada 7 dias, não deve ser utilizado em pacientes com sensibilidade conhecida a alginatos ou prata; não deve ser utilizado onde a presença de metais ; contraindicado para lesões resultante de infecções, como tuberculose, sífilis ou infecção fungica profunda, e para queimadura de terceiro grau. Deve ser usado em combinação com tratamento médico sistêmico adequado para tratamento da causa da infecção. Reduz o risco de maceração na área perilesional, maior tempo de uso e menor troca de curativos (POTTER PA e PERRY AG, 1999).

Hidrogel: tem a função de desbridamento autolítico, é indicado em feridas infectadas, colonizadas, cavitárias, em feridas com perda tecidual parcial ou profunda, feridas com tecido necrótico com pouco exsudato. Reduzem significativamente a dor, dando uma sensação refrescante, devido a sua elevada umidade que evita a desidratação das terminações nervosas. A troca deve ser realizada em feridas infectadas a cada 24 horas; necrose a cada 72 horas. Devido a reduzida capacidade de absorção, é contraindicada em feridas exsudativas. No entanto existem alguns produtos que associam o hidrogel ao alginato de cálcio, ampliando seu uso para feridas com moderado exsudato (COSTA FPP, 2005).

Hidrocolóide: possui forte capacidade de absorção. Capaz de absorver exsudato da ferida, formando um gel e favorecendo a formação de um ambiente úmido ideal para cicatrização. É indicado para feridas superficiais com volume pequeno de exsudação. Recomendado para gerenciamento de feridas com perda de tecido total ou parcial, de grau I-IV, não infectadas. Age em contato com a ferida, o hidrocolóide interage com o exsudato para formar um gel. O gel evita a aderência à ferida e proporciona alívio da dor, por manter úmidas as terminações nervosas. Deve ser trocado até 07 dias. Não se recomenda a utilização dos hidrocolóides em ferida clinicamente infectada. Lesões causadas por infecções crônicas, ao aplicar a cobertura deve ser assegurada margem de aproximadamente $2 \mathrm{~cm}$, para aderir à pele íntegra. $O$ gel criado pelo curativo pode ter aspecto característico e odor acentuado, não deve ser confundido com infecção (MÉLEGAJC, et,al., 2002).

Alginato de Cálcio reduz o exsudato, induz a hemostasia e auxilia no desbridamento autolítico, é remendado para tratamento de feridas com ou sem infecção, superficial, profundas, contendo túneis e fístulas com exsudato moderado alto, tais com: LP, lesões venosas e arteriais, lesão de pré-diabético, áreas doadoras de enxerto, feridas causadas por traumas, lesões dérmicas. O sódio do exsudato e o cálcio do alginato sofrem troca iônica formando um gel solúvel de alginato de sódio. Esse gel não é aderente à ferida. A geração de íon livre de cálcio amplifica a cascata de coagulação conferindo propriedades hemostáticas. A troca deve ser realizada a cada 7 dias. Não utilizar em implantes cirúrgicos ou queimaduras de terceiro grau; não utilizar simultaneamente com agentes tópicos, tais como antissépticos antibióticos: Askina Sorb possui poucos benefícios quando aplicado a feridas secas ou necróticas. Deve ser bem avaliado quanto sua indicação por ter custo elevado. É classificado como cobertura primaria, sendo necessária uma cobertura secundária (BORGES E, 2008).

Colágeno com Alginato de Cálcio e Sódio: combina resistência e apoio estruturado colágeno e as propriedades de formação de gel do alginato em curativo tópico macio, altamente absorvente e flexível. Ele mantém um microambiente fisiologicamente úmido na superfície da ferida que é condutivo à formulação de tecido de granulação, epitelização e faz com que a cicatrização ocorra mais rapidamente. É utilizado em lesões cavitárias, lesões de pressão, venosas, arteriais, diabética, área doadora da pele e outras lesões com 
sangramento não hemorrágico.Grande absorção de exsudato e mantém o meio úmido com formação de um gel. É contraindicado em lesões secas e com sensibilidade ao produto (COSTA FPP, 2005).

\section{CONSIDERAÇÕES FINAIS}

Ressalto que a prevenção é o melhor caminho e mais eficaz para evitar o aparecimento e a incidência das lesões por pressão. Mas se não for possível, o enfermeiro deve desempenhar papel decisivo no sucesso do tratamento das lesões por pressão, sendo ele o cuidador na prevenção, tratamento e cicatrização da ferida, baseando-se de acordo com o protocolo operacional padrão da instituição para desempenhar um bom procedimento, realizando a cicatrização da lesão já existente ou a prevenção de novas lesões.

\section{REFERÊNCIAS}

1. BORGES E. Feridas como tratar. Belo Horizonte: COOPMED, 2008.

2. BRADEN BJ, BERGSTROM N. Predictive validity of the Braden Scale for pressure sore risk in a nursing home population. Research in Nursin gand HealtHh, 1994; v.17, 459- 470.

3. BRANDÃO ES, et al. Um desafio no cuidado em enfermagem: prevenir úlceras por pressão no cliente. Rev. pesp. Cuid. Fundam, 2013; 5(1): 3221-28.

4. BRUNNER LS e SUDDARTH DS. Tratado de enfermagem médico-cirúrgica. Rio de Janeiro: Guanabara Koogan, $2011 ; 181 \mathrm{p}$.

5. CAMPEDELLI MC, et al. Escara: Problema na hospitalização. São Paulo: Ática, 1987.

6. CONCEIÇÃO GS, CALIRI MHL . Documento publicado na Revista ESTIMA, v. 5, n. 3. 2007.

7. COSTA FPP. Epidemiologia e Tratamento das Úlceras de Pressão: experiência de 77 casos. São Paulo, 2005.

8. CREMASCO MF, et al. Úlcera por pressão: risco e gravidade do paciente e carga de trabalho de enfermagem. Acta Paul Enferm. 2009; 22(n esp):897-902 p.

9. DEALEY C. Cuidando de feriadas: um guia para enfermeiras. 3 ed. São Paulo, 2008;134p.

10. DYNAMED P. Pressure ulcer. Ipswich (MA): EBSCO Information Services, 2017.

11. FERNANDES NCS, TORRES GV. Incidência e fatores de risco de úlceras de pressão em pacientes de unidade de terapia intensiva. CiencCuidSaude 2008;7(3): 304-310.

12. FREITAS MC de et al. Úlcera por pressão em idosos institucionalizados: análise da prevalência e fatores de risco. Rev. Gaúcha Enferm. (Online), Porto Alegre, v. 32, n. 1, 2011.

13. HANS M, et al. Fatores de risco adicionais à Escala de Braden: um risco para úlceras de pressão.Enfermagem em Foco 2011; 2(4):222-225.

14. IRION G. Feridas Novas abordagens, manejo clínico e Atlas em cores. Rio de Janeiro: Guanabara Koogan, 2005.

15. JUNQUEIRA LC, CARNEIRO J. Histologia básica: texto e atlas. 12.ed. Rio de Janeiro: Guanabara Koogan, 2013; $354 \mathrm{p}$.

16. LOURO M, FERREIRA M. Avaliação de protocolo de prevenção e tratamento de úlceras de pressão. São Paulo, 2007.

17. MARCON SS, LOPES MCL. Facilidades e dificuldades percebidas por enfermeiros na assistência à família. Online Braz J Nurs . 2008

18. MEDEIROS ABF, LOPES CHAF. Análise da prevenção e tratamento das úlceras por pressão propostos por enfermeiros. Rev. Esc. Enfermagem USP, 2009; 43(1): 223-8.

19. MÉLEGA JC. Cirurgia Plástica: Fundamentos e arte - Tronco e membros inferiores. Princípios Gerais. Rio de Janeiro: Medsi, 2002; 3-8.

20. MENEGON DB. Implantação do protocolo assistencial de prevenção e tratamentos de lesão por pressão no hospital de clínicas de Porto Alegre,2007.

21. POTTER PA, PERRY AG.Fundamentos de enfermagem. $4^{\text {a }}$ ed.v. 2 . Rio de Janeiro:Guanabara Koogan, 1999. SCHWARTS AY, et al. A atuação do enfermeiro frente a pacientes adultos hospitalizados com úlceras de pressão,2007.

22. SILVA RCL. Feridas: fundamentos e atualizações de enfermagem. São Paulo, 2011. 